\title{
A Manifestação da Timidez na Educação Infantil: Um Olhar Crítico e Reflexivo Sobre as Dificuldades e Ritmo de Aprendizagem
}

\author{
Maria do Socorro Gomes Filha ${ }^{1}$; Aurelania Maria de Carvalho Menezes ${ }^{2}$; \\ Maria do Socorro Cecílio Sobral ${ }^{3}$
}

\begin{abstract}
Resumo: Este artigo foi realizado a partir das reflexões no que diz respeito à manifestação da timidez em sala de aula das crianças em fase de desenvolvimento da aprendizagem, e foi embasado nas discussões de autores como Vygotsky 1989, ), Albisseti (1998) e Bravin (2013), dentre outros. O objetivo foi identificar quais os cuidados que a escola, professores e família devem ter com suas crianças tímidas. O autor citado traz a contribuição das interações sociais entre os sujeitos, considerando fundamental para o processo de aquisição de conhecimentos e da consciência. Na escola, a criança conviverá com outras pessoas da mesma idade e de diferentes faixas etárias, sendo assim, quais são as consequências da timidez e quando ela pode afetar o processo ensino-aprendizagem na construção dos conhecimentos e o que a escola pode fazer para colaborar com a sociabilidade dessas crianças? $\mathrm{O}$ trabalho foi impulsionado por tais questões. Investigou-se a timidez como fator prejudicial à aprendizagem e conclui que a escola deve auxiliar os alunos tímidos a se sentirem seguros no âmbito escolar. A pesquisa teve como justificativa que a timidez costuma não ser observada dentro das salas, pois a criança tímida não causa problemas, e com isso, não chama atenção. Constatou-se como resultados que a timidez excessiva prejudica a criança e cuidados devem ser tomados, pois envolve baixa-estima, interações, medos e privações, o que dificulta um desenvolvimento saudável em vários aspectos do processo ensino e aprendizagem. Diante disso, buscou-se abordar aqui os aspectos mais relevantes, apoiados no que orienta a Lei de Diretrizes e Bases - LDB nos art. 29,30 e 31. A qual vai além de um simples educar, busca a compreensão de como se processa e internaliza a aprendizagem de crianças tímidas.
\end{abstract}

Palavras-chave: Timidez. Aprendizagem. Educação Infantil

\section{The Manifestation of Shyness in Early Childhood Education: A Critical and Reflective Look at Difficulties and the Rhythm of Learning}

\begin{abstract}
This article was based on the reflections regarding the manifestation of shyness in the children's classroom in the learning development phase, and was based on the discussions of authors such as Vygotsky 1989, Albisseti (1998) and Bravin (2013), among others. The goal was to identify what care the school, teachers and family should have with their shy children. The cited author brings the contribution of social interactions between the subjects, considered fundamental for the process of knowledge acquisition and consciousness. At school, the child will be living with other people of the same age and of different age groups, thus, what are the consequences of shyness and when can it affect the teaching-learning process in the construction of knowledge and what can the school do to collaborate with the sociability of these children? The work was driven by such issues. Timidity was investigated as a detrimental factor to learning and concluded that the school should help shy students to feel safe in school. The research had as justification that the shyness usually is not observed inside the rooms, because the
\end{abstract}

\footnotetext{
${ }^{1}$ Faculdade de Ciências Humanas do Sertão Central (FACHUSC). E-mail: gomessocorro187@ gmail.com;

${ }^{2}$ Faculdade de Ciências Humanas do Sertão Central (FACHUSC). E-mail: lelamenezes@ yahoo.com.br;

${ }^{3}$ Mestrado em Educação em Ciências pela Fundação de Apoio à Universidade Federal do Rio Grande do Sul, Brasil. Professora da Faculdade de Ciências Humanas do Sertão Central (FACHUSC). E-mail: socorrosobral@ bol.com.br
} 
timid child does not cause problems, and with that, it does not call attention. It has been found that excessive shyness harms the child and care should be taken, as it involves low esteem, interactions, fears and deprivations, which hinders a healthy development in various aspects of the teaching and learning process. In view of this, we sought to address here the most relevant aspects, supported in what guides the Law of Guidelines and Bases articles 29, 30 and 31. Which goes beyond a simple education, seeks the understanding of how it is processed and internalized the learning of shy children.

Keywords: Shyness. Learning. Child education

\section{Introdução}

Inquietações, baseadas em experiências pessoais e profissionais, incitaram a realização da pesquisa com o tema timidez. O objetivo foi identificar quais os cuidados que a escola, professores e família devem ter com suas crianças tímidas. O estudo proporcionou que foi importante saber de que forma a timidez se manifesta nas pessoas e principalmente nas crianças e identificar quais são os maiores desafios que ela enfrenta quando começa a estudar. Na escola, ela conviverá com outras pessoas da mesma idade e de diferentes faixas etárias, sendo assim, quais são as consequências da timidez e quando ela pode afetar o processo ensino-aprendizagem na construção dos conhecimentos e o que a escola pode fazer para colaborar com a sociabilidade dessas crianças? O trabalho foi impulsionado por tais questões.

A timidez é um desconforto para crianças e adultos e ela é caracterizada pela inibição em situações que exijam algum tipo de interação pessoal, pois é notório que a timidez interfere na realização de objetivos tantos pessoais como profissionais. Quem é tímido, sofre com uma obsessiva preocupação relacionada às atitudes e pensamentos dos outros.

É comum encontrar nas escolas crianças que se apresentam tímidas, com dificuldade de estabelecer relações sociais com os amigos da turma, com os educadores e consigo mesma, causando dificuldades para expressar sua maneira de ser, sentir e agir no mundo escolar. Essas crianças com características mais introvertidas terminam sendo tratadas com certa negligência pelo fato de não serem vistas como "alunos problemas", pois como não dão trabalho para o professor e para a escola, são vistos como "bonzinhos", e acabam sendo considerados exemplos para os demais alunos, e consequentemente, deixam de receber a atenção devida.

Observa-se também, e deve ser trabalhado dentro das instituições escolares, que alunos tímidos estão mais expostos a agressões do que os outros. Geralmente, o aluno tímido, faz 
menos amizades, participam menos das relações de grupo, e isso favorece agressões, pois são considerados indefesos e não costumam revidar ou reclamar.

A metodologia do trabalho consiste numa abordagem qualitativa e dissertativa, após analisar e discutir teoricamente as questões acerca da timidez na educação infantil. A fonte de informações foi através de estudos bibliográficos, onde se analisou teorias de pesquisadores que nos deram subsídios para a construção do artigo, tais como: Vigotsky (1989), Albisseti (1998) e Bravin (2013), dentre outros, e com eles, foi estabelecida uma discussão com idéias e dos referidos autores.

\section{Referencial Teórico}

\section{Amparos legais da primeira modalidade da educação básica}

Sabe-se que a avaliação é um processo contínuo sobre uma ação em um contexto coletivo e é realizada para compreender algo específico e visa mudanças essencialmente necessárias no processo de ensino-aprendizagem na Educação Infantil. A avaliação deve permitir que o educador acompanhe a construção das muitas representações do aluno.

É relevante salientar que o professor da Educação Infantil deverá planejar a sua metodologia evidenciando as diferenças que encontrará em sala de aula, e assim desenvolver seu trabalho voltado para o pleno desenvolvimento cognitivo do aluno. Deve explorar as situações didáticas, experiência e manipulação de muitos objetos, assim como a realização de experiências específicas ao nível intelectual de cada um, não esquecendo da importância da participação da família nessa etapa tão significativa da vida da criança, conforme prega a LDB - Lei de Diretrizes e Base da Educação da Educação Infantil, No 9394/96, na Seção II nos artigos:

Art. 29- A educação infantil, primeira etapa da educação básica, tem como finalidade o desenvolvimento integral da criança até seis anos de idade, em seus aspectos físicos, psicológicos, intelectual e social, contemplando a ação da família e da comunidade.

Art. 30 - A educação Infantil será oferecida em:

I- Creches, ou entidade equivalentes, para crianças até três ano de idade;

II- Pré-escolas, para crianças de quatro a seis anos de idade;

Art. 31- Na educação infantil a avaliação far-se-á mediante acompanhamento e registro do seu desenvolvimento, sem o objetivo de promoção, mesmo para o acesso ao ensino fundamental. (BRASIL, 1996) 
Diante do que defende a referida lei, fica evidente a não utilização de outros métodos agressivos que venham a distorcer a forma de validação da aprendizagem da criança que se encontra em desenvolvimento inicial de sua vida escolar.

\section{O que é Timidez?}

Existem muitas teorias, mas é difícil encontrar uma definição exata para a timidez. Uma das mais aceitáveis é que a timidez é "a tensão e a inibição em situações sociais" (CHEEK \& BUSS, 1981, p. 330). Mas pode-se dizer que a melhor definição para tal comportamento é totalmente subjetivo, assim sendo, quem se acha tímido, é tímido e pronto.

Albisseti (1998) afirma que a timidez se manifesta em sintomas como: medo das pessoas, medo dos convites, medo de falar, medo de enrubescer, enfim, todos os medos que tendem a reduzir o contato com as pessoas e que trazem o isolamento. Assim sendo, a pessoa tímida prefere o isolamento a enfrentar determinados sentimentos

Na visão do senso comum ou pela própria visão do processo interno da criança, a timidez não compromete significativamente a realização pessoal, mas certamente acontece uma diminuição na qualidade de vida das pessoas tímidas. Isso é perceptível em diversas ocasiões sociais. Exemplos: dificuldades em participar de atividades grupal, de praticar esportes coletivos, falar em público, fazer perguntas em sala de aula, essas atitudes facilita o entendimento e ao mesmo tempo compreender as emoções que aquele aprendente está sentindo e intencionalmente demonstrando, mas não querer participar de determinadas situações não indica que a criança seja incapaz de realizá-las.

Bravin (2013) explica sobre alguns aspectos importantes da timidez:

A timidez limita o potencial natural que as pessoas possuem, pois, faz com que o ser humano não acredite em seu próprio poder físico e mental, ou seja, é como uma máquina potente que está inutilizada por não ter ninguém para operá-la (não pelo fato de não saber como manuseá-la, mas pelo fato de "achar" que não tem capacidade para isso, quando na verdade é o contrário. (BRAVIN, 2013).

É normal ou comum, que pessoas tímidas sintam medo de algum tipo de avaliação e elas ficam sempre atentas, pois sentem que existe sempre alguém observando seu comportamento, por isso, têm medo de expressar-se, de oralizar, da voz não sair no tom 
adequado ou de falar algo incorreto. Na maioria das vezes, uma fala simples entre outras pessoas torna-se apavorante.

Segundo Rampazzo (2009) afirma: as expressões gestuais e as muitas maneiras de falar são sinais de uma boa saúde, pois qualquer sentimento e emoção exagerado, tanto em relação à expressividade quanto a inexpressividade têm relação com a saúde humana.

Nesse sentido pode a pessoa tímida em sala de aula guardar suas dúvidas, pois prefere não falar, ou pedir explicação para o educador, e infelizmente e rotineiramente, muitos professores, sem preparação para lidar com a situação, acaba não intervindo, provocando a não aprendizagem do aluno tímido.

\section{A relação vivência-emoção-personalidade na compreensão histórico-cultural do processo da timidez.}

As definições de timidez são bem diversificadas e abrangentes. As emoções estão presentes e medo e vergonha aparecem como características predominantes em suas definições.

Sobre a relação existente entre personalidade e emoções, ressalta-se nas palavras de Vygotsky que:

Toda emoção é uma função da personalidade, e isto é justamente o que perde de vista a teoria periférica. Assim, a teoria puramente naturalista das emoções requer a modo de complemento, uma verdadeira e adequada teoria dos sentimentos humanos. Assim se impõe o problema de uma psicologia explicava das emoções. Esta psicologia descritiva busca uma via cientifica orientada aos problemas o espírito humano que os grandes autores resultam nas novelas e tragédias. (VYGOTSKY, 2004, p. 214).

Aqui o teórico deixa claro que, as emoções são essenciais à personalidade e não estão separadas da mente humana. Esta visão favorece a compreensão das emoções para além de outras teorias, visto que procuram entender as emoções como algo biológico.

Muito dos estudos descrevem a timidez como uma característica genérica da personalidade e um comportamento que se adapta ao meio em que o sujeito vive.

Torna-se importante salientar que a relação entre personalidade e meio social se mostra complexa de ser entendida, uma vez que Vygotsky (2006) ao se remeter à relação entre criança e o meio, declara que: 
para ele. Se a criança é um ser social e seu meio é o meio social, se deduz, portanto, que a própria criança, é parte do meio social. (VYGOTSKY, 2006, p. 381).

Assim, pode-se afirmar que o indivíduo faz parte do meio social, e não se apresenta enquanto algo isolado da realidade e do meio, ou que interfere neste como se fosse um ser a parte da realidade, mas o constrói, enquanto o meio o constitui, assim, são também o meio social. O desenvolvimento das capacidades esta internalizada e esse sentimento torna-se fruto que precisa amadurecer para o real desenvolvimento das capacidades.

Então, compreende-se que a pessoa tímida se manifesta de forma retraída e passiva, para proteger-se dos demais e de alguma situação social que pareça opressora, de uma situação de aparente exclusão, pois, na sociedade atual dada sua busca incessante por resultados imediatos e desempenhos individuais, muitas vezes, os sujeitos se protegem contra situações de opressão e discriminação.

\section{A manifestação da timidez na infância}

Não é raro ver criança que rói as unhas, com as mãozinhas sempre suadas, retraída, passiva, sem provocar diálogos e com dificuldade de relacionamentos com coleguinhas da mesma idade, pois é tímida.

As pessoas tímidas possuem bem mais dificuldade em fazer amizades. Para Axia (2003), o que se pressupõe é que mantenham mais vezes isoladas do que as outras crianças. Seguindo estas informações, Caballo e Simón, (2015), indica que o isolamento social na infância deve ser alvo de atenção, pois representa um padrão de respostas bastante inibidoras da aquisição de comportamentos adaptativos e pode provocar problemas de ajustamento por toda a vida.

Ainda não existe uma concordância entre os especialistas sobre a origem da timidez, muitos consideram que, apesar de genética, ela pode ser identificada a partir das relações estabelecidas com os outros. O não contato social durante a infância é um fator crucial para um mau desenvolvimento emocional. É importante o incentivo às interações desde cedo.

É necessária uma parceria efetiva entre os pais, a escola e professor, esse conjunto é decisivo neste processo e a timidez certamente desenvolverá se não houver uma luta contrária. 


\title{
A timidez na Educação Infantil e suas implicações no processo ensino aprendizagem.
}

Sabe-se que o primeiro ambiente de interação da criança é o familiar, estando ela, presente em toda a sociedade e mediando os padrões e modelos culturais.

Gonçalves (2008) salienta que:

\begin{abstract}
Além da família, a escola é um ambiente de fundamental importância para a aquisição de habilidades sociais, se a escola ignorar o repertório de comportamentos sociais da criança, ou o seu desenvolvimento interpessoal, ela colabora para a conservação ou a gravidade de conflitos. Esses conflitos, além de se constituírem um problema em si mesmo, atrapalham a aprendizagem, comprometendo também sua formação social. (GONÇALVES, 2008).
\end{abstract}

Diante dessa ressalva, é importante fazer com tais ambientes possam valorizar o desenvolvimento da criança, pois as habilidades alcançadas através delas são fundamentais para o equilíbrio emocional e social da criança.

De acordo com Caldas (2005), a escola contribuiu para a evolução da sociedade e da humanidade. Como um microssistema da sociedade, ela não apenas reflete as transformações atuais como também tem que lidar com as diferentes demandas do mundo globalizado. A observação de Caldas dá a devida importância à escola, dando a ela um status de facilitador do conhecimento.

Del Prette (2008) fala do cotidiano escolar da criança e diz que:

\begin{abstract}
Na escola, o educador deve observar a criança em várias situações diárias e, com isso, analisar em quais momentos ela se sente mais ou menos à vontade para a criança ampliar seu conjunto de relações compartilhando sua vida com outras crianças e adultos, sendo de fundamental importância para a aquisição de habilidades sociais (DEL PRETTE, 2008).
\end{abstract}

Santos (2014) descreve que, no contexto escolar, professores qualificam crianças tímidas como quietas e medrosas, geralmente não as identificam como indivíduos com problemas, sendo muitas das vezes valorizados como bons alunos, já que seus comportamentos não perturbam. Mas é importante observar os muitos comportamentos em sala, pois até mesmo, as crianças caladas e não ativas merecem uma atenção especial, para identificar o que as levam ao afastamento do grupo.

De acordo com Del Prett (2008), a forma de aprendizagem das crianças, seu desempenho escolar e o valor a ele atribuído podem constituir-se em condições de proteção ou 
de vulnerabilidade para o desenvolvimento. Então, percebe-se que um bom desempenho certamente favorece a superação de dificuldades e propicia o envolvimento em muitos projetos que potencializam uma vida de realizações. Mas Santos (2014) alerta que os problemas escolares, por sua vez, podem acentuar as dificuldades e as vivências de menos-valia, condições estas favorecedoras de outras dificuldades comportamentais e emocionais .

Durante a fase escolar, o ambiente do lar costuma afetar o desempenho e o ajustamento à escola. Práticas educativas negativas, os conflitos e carência de afetividade entre pais e filhos aumentam o risco de problemas emocionais e comportamentais, e a timidez pode ser um deles. Por outro lado, e conforme Amaro (2006), práticas educativas positivas, estruturação de regras e rotinas no lar, o suporte à autonomia, o envolvimento dos pais com a escolaridade dos filhos e a oferta de atividades sociais e enriquecedoras durante os anos da escola favorecem o bom desempenho escolar, sociabilidade na sala de aula, autorregulação e percepção de controle por parte da criança (AMARO, 2006).

As experiências positivas na escola proporcionam trocas interpessoais aumentam as chances de desenvolvimento de um repertório diverso de estratégias de adaptação para enfrentar com autonomia os desafios da vida em comunidade. Mas por outro lado, Caldas (2005) diz que o aspecto negativo, pode afetar o desenvolvimento com uma limitação de repertório, interferir negativamente na formação do senso de autoestima reduzindo suas chances de desenvolver um fator de resiliência frente a adversidades futuras e contribuir para aumentar a vulnerabilidade da criança, exposta a um ambiente físico e social estranho (CALDAS, 2005).

Diante do exposto, evidenciou-se que vários fatores podem contribuir para que a aprendizagem da criança seja comprometida, mas há suportes que podem inverter tal processo. Se a timidez for logo percebida pelo professor, e este não excluir o aluno por comodidade ou por considerar a criança com bom comportamento por ser tímida, ele poderá ajudar não excluindo e sim, incentivando a participação e proporcionando ocasiões para que a criança possa interagir sem constranger-se.

\section{Metodologia}

O trabalho traz em uma abordagem qualitativa e dissertativa sobre o tema em estudo, após analisar e discutir teoricamente as questões acerca da timidez na educação infantil, e que 
a criança precisa ser bastante trabalhada para que adquiram seus primeiros ensinamentos que mais tarde serão concretizados com sucesso.

A fonte de informações aconteceu através de estudos bibliográficos, onde se analisou várias teorias de alguns pesquisadores que nos deram subsídios para a construção do pensamento sobre o tema em estudo, tais como: Vigotsky (1989), Albisseti (1998) e Bravin (2013), dentre outros, e com eles, foi estabelecida uma discussão positiva com idéias expostas dos referidos autores.

\section{Resultados e Discussões}

A pesquisa traz como resultados ao trabalho do educador a percepção de que é necessário munir-se de instrumentos que lhes favoreça um desempenho integral de suas funções, de suas capacidades e produções, podendo a qualquer momento ser replanejada a ação educativa, principalmente no momento em que acontece o afronte com a timidez do aluno.

Nesse sentido corrobora Vygotsky (1989 p. 125):

\footnotetext{
O professor não deve levar em conta, como ponto de partida para a ação pedagógica, apenas o que a criança já conhece ou faz, mas principalmente, deve levar em conta suas potencialidades cognitivas, fazendo outros desafios e mais exigente no sentido de envolvê-las em novas situações de modo a provocá-las, permanentemente, à superação cognitiva e a quebra da timidez.
}

O estudo mostrou que ser humano aperfeiçoou a forma de comunicação com o passar do tempo e assim, no trato com outras pessoas, foi deixando ou eliminando aos poucos expressões gestuais e sussurros e passou a utilizar a fala para comunicar-se e aos poucos ela foi sendo refinada, transformando-se em linguagem verbal. Posteriormente, a humanidade desenvolveu outra forma de comunicação, a escrita, que facilitou a comunicação à distância.

Através da pesquisa compreendeu-se que timidez se expressa e se constitui, também, através de características biológicas e o meio social é relevante em sua concepção. Mas é importante defender que este processo de internalização existente entre o meio social e a personalidade não acontece através de uma transposição mecânica e não são exclusivos dos processos fisiológicos e neurológicos.

Notou-se com o estudo que as crianças tímidas têm dificuldade em manter relacionamentos com outras crianças porque precisam de habilidades sociais, e se não fazem 
amizades, se tornam mais solitárias. Assim surgem, as dificuldades de defesa, de brincadeiras agressivas e muitas crianças interpretam isso como indiferença, e elas terminam sendo ignoradas ou excluídas.

Corrobora quando afirma Santos (2014): O desenvolvimento sócio emocional se processa através de desafios próprios de cada etapa da vida. A resolução satisfatória ou o fracasso em uma dada etapa influenciam as etapas posteriores.

Assim sendo, tanto família, como escola, devem observar que muitas ações das crianças e devem ser consideradas através de orientações no convívio para estas tenham bons relacionamentos.

\section{Considerações Finais}

Vários pontos contribuíram para a construção e progresso do referido trabalho, como por exemplo, a questão da auto-identificação com o tema pesquisado.

Ao longo das muitas pesquisas percebeu-se que existem muitos professores que não incentivam o aluno tímido, pois acham mais cômodo deixá-lo em seu canto e o impede de uma maior interação em sala de aula.

Atividades que envolvem grupos e que mostram ao aluno sua importância no meio escolar são importantes para que aconteça uma maior segurança dos alunos em relação a eles mesmos, pois evidenciou-se que a timidez não é somente uma forma de conduta comportamental e sim algo que vem acompanhado de várias outras questões afetivas, sócioafetivas, emocionais e psicológicas.

O referido artigo mostrou que o desabrochar na Educação Infantil é um processo contínuo onde se busca crescimento do educando na perspectiva de uma construção inovadora em seus diferentes aspectos.

A visão impar é de suma importância para melhor desenvolvimento, e o educador tem que ser paciente participativo e ativo, e a partir de várias indagações, acompanhamentos e estudos, consequentemente, mudar o quadro educacional e trazer o que é de melhor para o educando. 
Referências

ALBISSETTI, Valério. Pode-se vencer a timidez? São Paulo: Paulinas. 1998

AMARO, Deigles G. Psicologia e Educação: Educação Inclusiva, Aprendizagem e Cotidiano Escolar. $1^{\circ}$ Ed. São Paulo: Casa do Psicólogo, 2006.

AXIA, G. A Timidez: Um dote precioso do patrimônio genético humano. 3. Ed. São Paulo: Loyola, 2003.

BRASIL, LDB - Lei de Diretrizes e Base da Educação da Educação Infantil, Nº 9394/96.

BRAVIN, Pablo de Paula. Como acabar com a timidez. 2013. Disponível em: < http://networking.com.vc/artigos/como-acabar-com-a-timidez> . Acesso em: setembro. 2018

CABALLO, Vicente E.; SIMÓN, Miguel Ángel. Manual de psicologia clínica infantil e do adolescente: transtornos específicos. 1 ed. Reimpr. São Paulo: Santos, 2015.

CALDAS, C.F.A. Monografia: Auto Estima e Timidez Infantil. Brasília/DF, 2005. Faculdade De Ciências Da Saúde.

CHEEK, J. M., e Buss, A. H. (1981). Shyness and sociability. Journal of Personality and Social Psychology, 21, 1, 330 - 339.

COLL, Cezar; MARCHESI, Álvaro; PALACIOS, Jesús; COLS. Transtornos de desenvolvimento e necessidades educativas especiais. Porto Alegre: Artimed, 2010.

DEL PRETTE, A. e DEL PRETTE, Z. A. P. (203-2005-2008). Psicologia das Habilidades Sociais na Infância - Teoria e Prática. Petrópolis: Vozes. 2008

GONÇALVES, E. S.; MURTA, S. G. Avaliação dos Efeitos de uma Modalidade de Treinamento de Habilidades Sociais para Crianças, 2008.

RAMPAZZO, Lisnéia. Psicologia geral. São Paulo: Pearson Education, 2009.

SANTOS, F.M. Monografia: Consequências Psicológicas e Sociais da Timidez. Caruaru, 2011. Faculdade do Vale do Ipojuca - Favip.

VYGOTSKY, L. S. A Formação Social da Mente. São Paulo, Martins Fontes, 1989.

. Pensamento e Linguagem. São Paulo: Martins Fontes. 1987.

Teoria das emocões: estudo histórico-psicológico. Madrid: Akal, 2004 (Texto original de 1933). 


\section{Como citar este artigo (Formato ABNT):}

GOMES FILHA, Maria do Socorro; MNEZES, Aurelania Maria de Carvalho; SOBRAL, Maria do Socorro Cecílio. A Manifestação da Timidez na Educação Infantil: Um Olhar Crítico e Reflexivo Sobre as Dificuldades e Ritmo de Aprendizagem. Id on Line Rev.Mult. Psic., 2018, vol.12, n.42, Supl. 1, p. 588-599. ISSN: 1981-1179.

Recebido: 08/11/2018;

Aceito: $12 / 11 / 2018$ 